\title{
Analisis Permintaan Konsumen Rumah Tangga terhadap Minyak Goreng Curah di Kota Denpasar
}

\author{
I MADE ADI DWIRANA PUTRA, \\ KETUT BUDI SUSRUSA, NI WAYAN PUTU ARTINI
}

\author{
Program Studi Agribisnis, Fakultas Pertanian, Universitas Udayana \\ Jl. PB. Sudirman Denpasar 80232 Bali \\ Email: madedwirana@gmail.com \\ kbsusrusa@yahoo.co.id
}

\begin{abstract}
Analysis Of Household Consumer Demand On Bulk Cooking Oil in Denpasar City

Nowadays cooking oil is sold in two forms; one is referred to as bulk cooking oil 'minyak goreng curah' and the other is referred to as packaged cooking oil 'minyak dalam kemasan' with a particular trademark. However, the consumers in Denpasar still prefer the bulk cooking oil to the packaged cooking oil. This present study was intended to identify the factors contributing to the demand for the bulk cooking oil and the elasticity of the demand in Denpasar City. The study was conducted at Satrya Market, Sanglah Market, Kreneng Market, and Badung Market, which were all purposively determined. The samples were taken using the accidental sampling technique, totaling 40 and were purposively determined. This research uses Cobb-Douglas function with transformed data. The independent variables were $X_{1}$ (the price of the bulk cooking oil), $\mathrm{X}_{2}$ (the price of the packaged cooking oil), $\mathrm{X}_{3}$ (the price of chicken), $\mathrm{X}_{4}$ (the number of family members), and $\mathrm{X}_{5}$ (the family income). The result of the model was as follows $\ln Y=-5,876-2.184 \ln \mathrm{X}_{1} *+3.588 \ln \mathrm{X}_{2} *-0.332 \ln \mathrm{X}_{3}+0.311 \ln \mathrm{X}_{4} *+0.244 \ln \mathrm{X}_{5} *$. The factors which contributed to the demand for the bulk cooking oil were its price, the price of the packaged cooking oil, the price of chicken, the number of family members, and the family income. The price of the bulk cooking oil showed elasticity. The cross elasticity showed that the packaged cooking oil was a substitution commodity and that chicken was a complementary commodity. The income elasticity showed that the bulk cooking oil was an inferior commodity.
\end{abstract}

Keywords: bulk cooking oil, demand, elasticity

\section{Pendahuluan}

\subsection{Latar Belakang}

Kebutuhan pokok pada dewasa ini semakin beragam dan semakin meningkat. Salah satu yang wajib dipenuhi manusia adalah kebutuhan pangan (Winarno, 2004).Kebutuhan pangan yang termasuk ke dalam sembilan bahan pokok (sembako) adalah sembilan jenis kebutuhan pokok masyarakat yang terdiri atas berbagai bahanbahan makanan dan minuman yang sebagian besar dihasilkan dari sektor pertanian. Sembilan bahan pokok tersebut menurut keputusan Menteri Industri dan 
PerdaganganNo.115/mpp/kep/2/1998 adalah beras, sagu dan jagung, sayur-sayuran dan buah-buahan, daging (sapi atau ayam), minyak goreng dan margarin, susu, telur, minyak tanah atau gas elpiji, garam beryodium atau bernatrium. Sembako yang sering dijumpai di rumah tangga adalah minyak goreng. Minyak goreng yang sering digunakan adalah minyak goreng sawit yang cukup ideal dari segi harga dan ketersediaannya(Amang 1996, dalam Wijana, 2004). Daerah penghasil minyak goreng kelapa sawit sebagian besar ada di pulau Jawa, Sumatra bahkan Kalimantan. Pulau Bali merupakan salah satu langganan masuknya minyak kelapa sawit tersebut.

Minyak goreng yang terdapat pada makanan yang digoreng berfungsi sebagai medium penghantar panas, menambah rasa gurih, menambah nilai gizi dan kalori dalam tubuh (Ketaren, 2008). Minyak goreng yang saat ini beredar di pasaran terdapat dalam dua jenis, yaitu minyak goreng kemasan (merek apapun) dan minyak goreng curah dimana perbedaan yang paling terlihat adalah padapengemasannya. Minyak goreng curah hanya menggunakan plastik kiloan, namun kualitasnya masih layak untuk digunakan sebagai pengolah makanan dengan penggunaan sewajarnya.

Pandanganmelalui sisi ekonomi maka rumah tangga merupakan unit terbesar aktivitasnya dalam mengabiskan utility dari minyak goreng curah karena tingginya pemenuhan kebutuhan kalori (kkal) per hari masyarakat yang bisa diperoleh dari makanan yang diolah dengan minyak goreng terutama minyak goreng curah khususnya bagi masyarakat Kota Denpasar.Data Badan Pusat Statistika Provinsi Bali, Kota Denpasar menjadi kontributor terbesar pada sektor konsumsi makanan Tahun 2015 hingga 2016. Sedangkan, menurut data Dinas Perindustrian dan Perdagangan Kota Denpasar per tanggal 20 September 2017 menunjukkan harga minyak goreng curah berada pada harga Rp.12.000/kg di beberapa pasar tradisional Kota Denpasar. Hal demikian menyebabkan minyak goreng curah masih bisa bersaing diantara minyak goreng kemasan dilihat dari segi harganya.

Berdasarkan uraian diatas, peneliti ingin mengetahui faktor-faktor apa saja yang mempengaruhi permintaan minyak goreng curah dan mengetahui elastisitasnya baik dari elastisitas harga, elastisitas silang maupun elastisitas pendapatan konsumen, khususnya konsumen rumah tangga di Kota Denpasar, Provinsi Bali.

\subsection{Rumusan Masalah}

Beredarnya berbagai macam minyak goreng kemasan dengan merek - merek tertentu di pasaran tidak menyebabkan minat konsumen rumah tangga dalam mengkonsumsi minyak goreng curah menurun, maka rumusan masalah yang dapat diuraikan sebagai berikut.

1. Faktor-faktoryang mempengaruhi permintaan minyak goreng curah di Kota Denpasar.

2. Besar elastisitas permintaan minyak goreng curah oleh konsumen rumah tangga di Kota Denpasar akibat dari elastisitas harga, elastisitas silang, dan elastisitas pendapatan. 


\subsection{Tujuan Penelitian}

Berdasarkan permasalahan diatas dengan marak beredarnya minyak goreng kemasan di pasaran, tujuan dari penelitian ini yang ingin dicapai antara lain:

1. Mengidentifikasi fakor-faktor yang mempengaruhi permintaan konsumen terhadap minyak goreng curah di Kota Denpasar, Provinsi Bali.

2. Mengetahui dan Menganalisis elastisitas permintaan minyak goreng curah di Kota Denpasar, Provinsi Bali.

\section{Metode Penelitian}

\subsection{Lokasi dan Waktu Penelitian}

Penelitian dilakukan mulai bulan Februari sampai dengan bulan April 2018dilakukan di Kota Denpasar Provinsi Bali, tepatnya di Pasar Badung, Pasar Kreneng, Pasar Satrya, dan Pasar Sanglah. Menurut data Perusahaan Daerah (PD) Pasar Kota Denpasar, pasar-pasar tersebutdipilih karena keempat pasarmerupakan pasar tradisional dengan jumlah pedagang terbesar di masing-masing kecamatan di Kota Denpasar.

\subsection{Data dan Metode Pengumpulan Data}

Data dalam penelitian ini berupadata kuantitatif dan data kualitatif yang berasal dari sumber primer dan sumber sekunder. Metode pengumpulan data yang digunakan adalahobservasi, wawancara, dan studi dokumentasi.

\subsection{Penentuan Sampel Penelitian}

Populasi dalam penelitian ini adalah konsumen rumah tangga yang menggunakansekaligus melakukan pembelian minyak goreng curah di Pasar Badung, Pasar Kreneng, Pasar Satrya, dan Pasar Sanglah dengan jumlah yang tidak ditentukan.Sampel diambilmenggunakan metode sampling secara kebetulan atau accidental sampling sebanyak 40 sampel.

\subsection{Variabel Penelitian}

Variabel dan pengukuran yang digunakan dalam penelitian ini adalah analisis permintaan dan elastisitas permintaan minyak goreng curah. Variabel-variabel tersebut menjelaskan adanya variabel bebas dan variable terikat.Variabel terikat dalam penelitian ini adalah jumlah permintaan minyak goreng curah $(\mathrm{kg} / \mathrm{bulan})$. Variabel bebas dalam penelitian ini meliputi harga minyak goreng curah $(\mathrm{Rp} / \mathrm{kg})$, harga minyak goreng kemasan $(\mathrm{Rp} / \mathrm{kg}$ ), harga daging ayam ( $\mathrm{Rp} / \mathrm{kg}$ ), jumlah anggota rumah tangga (orang), dan pendapatan rumah tangga (Rp/bulan).Elastisitas permintaanminyak goreng curahditinjau dari elastisitas harga, elastisitas silang, dan elastisitas pendapatan.

\subsection{Metode Analisis Data}

Metode analisis yang digunakan dalam penelitian ini adalah analisis kuantitatif dan deskriptif kualitatif dari data pendukung. Analisis yang digunakan untuk menjawab permasalahan pertama adalah fungsi permintaan Cobb-Douglasdengan data yang 
ditransformasi ke dalam bentuk logaritma natural. Persamaan Cobb-Douglas pada umumnya ditulis sebagai berikut.

$$
\mathrm{Y}=\beta_{0} \mathrm{X}_{1}^{\beta 1} \mathrm{X}_{2}^{\beta 2} \mathrm{X}_{3}^{\beta 3} \mathrm{X}_{4}^{\beta 4} \mathrm{X}_{5}^{\beta 5}
$$

Menghindari munculnya data nonlinier akibat dari variabel bebas yang berfungsi pangkat maka model fungsi permintaan Cobb-Douglas diatas dapat ditransformasikan ke dalam bentuk logaritma natural (LN) yang diperoleh dengan bantuan softwareSPSS 23 sehingga persamaan modelnya adalah sebagai berikut.

$$
\ln \mathrm{Y}=\quad \ln \beta_{0}+\beta_{1} \ln \mathrm{X}_{1}+\beta_{2} \ln \mathrm{X}_{2}+\beta_{3} \ln \mathrm{X}_{3}+\beta_{4} \ln \mathrm{X}_{4}+\beta_{5} \ln \mathrm{X}_{5}+\varepsilon_{\mathrm{i}}
$$

dimana:

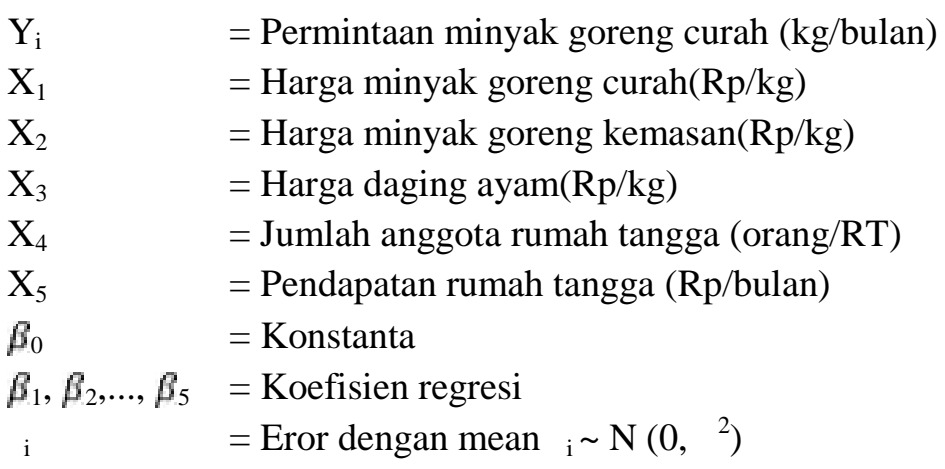

Mengetahui apakah model telah memenuhi presyaratan BLUE (Best Linier Unbiased Estimator) melaluipengujian tersebut meliputiuji asumsi klasik dan uji statistik. Uji asumsi klasik terdiri dari uji normalitas dengan metode kolmogorovsmirnov, uji multikolinearitas dengan metode TOL dan VIF, dan uji heteroskedastisitas dengan metode glejser. Uji statistik terdiri dari uji koefisien determinasi $\left(\mathrm{R}^{2}\right)$, uji pengaruh secara simultan(uji F), dan uji pengaruh secara parsial (uji t).Selanjutnya, elastisitas permintaan (harga, silang dan pendapatan) dapat dilihat dari masing-masing koefisien regresi pada model yang dihasilkan.

\section{Hasil dan Pembahasan}

\subsection{Karakteristik Responden}

Usia dan jumlah anggota rumah tangga, responden yang membeli minyak curah di pasar tradisional adalah 26 tahun sampai59 tahun dengan rata-rata umur responden yaitu 43 tahun. Jumlah anggota rumah tangga responden yang ditemukan membeli minyak goreng curah adalah lebih banyak memiliki anggota empat orang dimana biasanya terdiri dari ayah, ibu dan dua orang anak.

Tingkat pendidikan yang mendominasi membeli minyak goreng curah adalah tingkat pendidikan SMA yaitu sejumlah 17 orang. Pekerjaan yang dominan ditemukan yaitu ibu rumah tangga karena ibu rumah tangga memiliki banyak waktu untuk mengurus kebutuhan rumah tangga.

Tingkat pendapatan responden yang membeli minyak goreng curah di pasar tradisional adalah rumah tangga dengan total pendapatan dua juta hingga tujuh juta 
keatas dengan rata-rata pendapatan responden sebesar Rp. 4.946.250/bulan, namun pendapatan tujuh juta keatas paling sedikit ditemukan di pasar tradisional karena umumnya masyarakat yang berpendapat tinggi cenderung berbelanja di pasar modern.

\subsection{Perilaku Responden dalam Pembelian Minyak Goreng Curah}

Prilaku responden yangmembeli minyak goreng curah $1 \mathrm{~kg}$ sebanyak 23 orang dan $2 \mathrm{~kg}$ sebanyak 17orang denganrata-rata frekuensi pembelian minyak goreng curah responden besar paling adalah tujuh kali sebulan. Konsumsi yang sewajarnya dalam porsi rumah tangga dan habis dalam sekali pemakaian tujuannya mencegah minyak goreng curah yang mudah rusak apabila disimpan terlalu lama.

Respon responden mengenai perubahan harga minyak goreng curah dan pendapatan yaitu (1) Ketika harga minyak goreng curah naik sebagian besar akan mengurangi pembelian minyak goreng curah dari biasanya, dan (2) ketika pendapatan naik sebagian besar akan mengurangi pembelian minyak goreng curah dan beralih membeli minyak goreng kemasandikarenakan perbedaan harga yang tidak terlalu signifikan antara keduanya.

\subsection{Uji Ketepatan Model}

Uji ketepatan dari model faktor-faktor yang mempengaruhi permintaan konsumenterhadap minyak goreng curah di Kota Denpasar dilakukan dengan fungsi permintaan Cobb-Douglas dengan data ditransformasi ke dalam bentuk logaritma natural (LN) menggunakan software SPSS 23. Hasil analisisnyaakan disajikan pada tabelberikut.

Tabel 1.

Hasil Uji Asumsi Klasik

\begin{tabular}{|c|c|c|c|c|}
\hline \multirow{2}{*}{$\begin{array}{c}\text { Fungsi } \\
\text { Permintaan }\end{array}$} & \multicolumn{4}{|c|}{ Uji asumsi klasik } \\
\hline & Normalitas & Multik & nearitas & Heterokedastisitas \\
\hline $\begin{array}{l}\text { Cobb-Douglas } \\
\text { dengan } \\
\text { datayang } \\
\text { ditransformasi } \\
\text { ke dalam bentuk } \\
\text { logaritma } \\
\text { natural (ln) }\end{array}$ & $\begin{array}{c}\text { Kolmogorov-Smirnov } \\
\text { menunjukkan } \\
\text { Asymp.sig }=0,181\end{array}$ & $\begin{array}{c}\text { Nilai } \\
\text { Tolerance } \\
\text { X1 }=0,911 \\
\text { X2 }=0,907 \\
\text { X3 }=0,828 \\
\text { X4 }=0,763 \\
\text { X5 }=0,629\end{array}$ & $\begin{aligned} & \text { Nilai VIF } \\
& \text { X1 }=1,098 \\
& \text { X2 }=1,103 \\
& \text { X3 }=1,207 \\
& \text { X4 }=1,311 \\
& \text { X5 }=1,591\end{aligned}$ & $\begin{aligned} \text { P-Value } & \\
X 1 & =0,053 \\
X 2 & =0,824 \\
X 3 & =0,051 \\
X 4 & =0,735 \\
X 5 & =0,874\end{aligned}$ \\
\hline
\end{tabular}

Sumber : Data Primer (2018)

Berdasarkan tabel diatas dapat diperoleh hasil sebagai berikut.

1. Uji asumsi klasik

a) Uji normalitas, dimana hasil analisis menunjukkan bahwa nilai Asymp.sig pada pengujian melalui metode kolmogorov-smirnov bernilai 0,181. Tingkat signifikansi (alpha) adalah 0,05 atau 5\% dikatakan bahwa 0,181>0,05. Kesimpulannya, maka dengan tingkat signifikansi 5\%, nilai residual terstandarisasi dari model ini terdistribusi normal. 
b) Uji multikolinearitas, dimana hasil analisis menunjukkan bahwa semua variabel bebas dalam model memiliki nilai TOL lebih besar dari 0,10 dan nilai VIF lebih kecil dari 10. Kesimpulannya model regresi yang dihasilkan tidak terjadi gejala multikolinieritas.

c) Uji heteroskedastisitas, menunjukkan bahwa nilai signifikansisemua variabel bebas pada tabel adalah lebih besar dari nilai alpha $(\alpha=0,05)$. Kesimpulannya model regresi yang dihasilkan tidak mengandung gejala heterokedastisitas.

2. Uji statistik

Hasil analisis uji statistik dapat dilihat pada tabel berikut

Tabel 2.

Hasil Uji Statistik

\begin{tabular}{c|ccc}
\hline \multirow{2}{*}{ Fungsi Permintaan } & \multicolumn{3}{c}{ Uji statistik } \\
\cline { 2 - 4 } \multicolumn{1}{c}{ Uji R $^{2}$} & Uji F & Uji t \\
\hline Cobb-Douglas dengan data yang & & & p-value : \\
ditransformasi ke bentuk logaritma & 0,590 atau 59\% & p-value $=$ & $\mathrm{X} 1=0,001$ \\
natural (ln) & & 0,000 & $\mathrm{X} 2=0,000$ \\
& & & $\mathrm{X} 3=0,789$ \\
& & $\mathrm{X} 4=0,001$ \\
& & $\mathrm{X} 5=0,010$ \\
\hline
\end{tabular}

Sumber : Data Primer

a) Uji koefisien determinasi $\left(\mathrm{R}^{2}\right)$, menunjukkan bahwa nilai koefisien determinasi dari model yang dihasilkan adalah sebesar 0,590. Nilai 0,590 menunjukkan bahwa sebesar 59\% mempengaruhi permintaan minyak goreng curah sedangkan sisanya $41 \%$ dijelaskan variabel lain yang tidak dimasukkan dalam model.

b) Uji pengaruh secara simultan (uji F), menunjukkan bahwa variabel bebas secara simultan berpengaruh signifikan terhadap permintaan minyak goreng curah karenanilai probabilitas atau P-value (sig.) yang dihasilkan sebesar 0,000 lebih kecil dari taraf nyata $(\alpha=0,05)$.

c) Uji pengaruh secara parsial (uji t), dimana hasil uji pada Tabel 3 berikut bahwasemua variabel bebas berpengaruh signifikan secara sendiri-sendiri kecuali variabel harga daging ayam $\left(\mathrm{X}_{3}\right)$. Terbukti semua variabel bebas memiliki nilai $\mathrm{p}$ value lebih kecil dari alpha $(0,05)$.

Tabel 3.

Hasil Uji Pengaruh SecaraParsial (Uji t)

\begin{tabular}{lcrrr}
\hline \multicolumn{1}{c}{ Variabel } & Koefisien & Std. eror & \multicolumn{1}{c}{ t-hitung } & p-value \\
\hline Konstanta & -5.876 & 14,252 & $-0,412$ & 0,683 \\
Harga minyak goreng curah $\left(\mathrm{X}_{1}\right)$ & $-2,184$ & $-0,413$ & $-3,594$ & $0,001^{*}$ \\
Harga minyak goreng kemasan $\left(\mathrm{X}_{2}\right)$ & 3,588 & 0,608 & 5,272 & $0,000^{*}$ \\
Harga daging ayam $\left(\mathrm{X}_{3}\right)$ & $-0,332$ & $-0,033$ & $-0,270$ & 0,789 \\
Jumlah anggota rumah tangga $\left(\mathrm{X}_{4}\right)$ & 0,311 & 0,469 & 3,733 & $0,001^{*}$ \\
\hline
\end{tabular}




\begin{tabular}{lcccc}
\hline Total pendapatan rumah tangga $\left(\mathrm{X}_{5}\right)$ & $-0,244$ & $-0,378$ & $-2,730$ & $0,010^{*}$ \\
\hline R-Square $\left(\mathrm{R}^{2}\right)=59 \%$ & $\mathrm{R}$-Square $($ Adj $)=53 \%$ p-value $=0.000$
\end{tabular}

Sumber : Data Primer

Keterangan: $*=p<0,05$

\subsection{Faktor-faktor yang Mempengaruhi Permintaan Minyak Goreng Curah}

Berdasarkan hasil pada Tabel 3, maka koefisien dimasukkan kedalam model persamaan fungsi Cobb-Douglas dengan data ditransformasi ke logaritma natural (LN) adalah sebagai berikut.

$\ln Y=-5.876-2,184 \ln X_{1}+3,588 \ln X_{2}-0,332 \ln X_{3}+0,311 \ln X_{4}-0,244 \ln X_{5}$

Hasil uji pengaruh secara parsial menunjukkan bahwa harga minyak goreng curahberpengaruh signifikan terhadap permintaan minyak goreng curah di Kota Denpasar. Nilai koefisien regresi variabel harga minyak goreng curah adalah-2,184 (bernilai negatif) artinya jika harga naik satu persen maka jumlah permintaan minyak goreng curah turun sebesar 2,184\%, begitu sebaliknya (ceterus paribus).

Harga minyak goreng kemasan berpengaruh signifikan terhadap permintaan minyak goreng curah di Kota Denpasar dengan nilai koefisien regresi adalah 3,588 (bernilai positif). Nilai koefisien regresi bernilai positif artinya jika harga minyak goreng kemasan naik maka jumlah permintaan minyak goreng curah juga meningkat begitupun sebaliknya (ceterus paribus). Hasil penelitian ini sesuai dengan hasil penelitian Berry (2014) yang berjudul "Faktor-faktor yang Mempengaruhi Permintaan dan Penawaran Minyak Goreng Curah di Kota Medan" dimana dikatakan semakin meningkat harga minyak goreng kemasan maka permintaanya semakin menurun dan konsumen mulai beralih ke minyak goreng curah yang harganya murah sehingga dikatakan sebagai barang substitusi begitupun sebaliknya.

Hasil uji pengaruh secara parsial menunjukkan bahwa harga daging ayam tidak berpengaruh signifikan terhadap permintaan minyak goreng curah, namun dari koefisien regresi menjelaskan $-0,332$ artinya jika harga daging ayam naik sebesar satu persen maka permintaan minyak goreng curah akan menurun sebesar $0,332 \%$. Nilai tidak berpengaruh signifikan maka pada elastisitas permintaan, variabel daging ayam tidak dibahas.

Berdasarkan Tabel 3, variabeljumlah anggota rumah tanggaberpengaruh signifikan terhadap permintaan minyak goreng curah di Kota Denpasar. Nilai koefisien regresi variabel jumlah anggota keluarga adalah sebesar 0,311 (bernilai positif) artinya bahwa jika jumlah anggota keluarga bertambah sebesar satu persen, maka jumlah permintaan minyak goreng curah akan meningkat sebesar $0,311 \%$ dan begitu pula sebaliknya (ceteris paribus).

Variabel pendapatan rumah tangga juga berpengaruh signifikan terhadap permintaan minyak goreng curah, sedangkan koefisien regresinya sebesar $-0,244$ bernilai negatif yang berarti apabila pendapatan meningkat sebesar satu persen akan diikuti penurunan permintaan minyak goreng curah sebesar $0,244 \%$. Hal ini sesuai dengan hasil penelitian Darnilawati (1998) yang berjudul "Analisis Permintaan 
Konsumen terhadap Minyak Makan di Kota Pekanbaru" dimana dikatakan kenaikan pendapatan mempengaruhi konsumen memilih mutu minyak makan yang akan dikonsumsi yaitu dari minyak goreng curah ke minyak goreng kemasan.

\subsection{Elastisitas Permintaan Minyak Goreng Curah}

Elastisitas pemintaan minyak goreng curah dapat dilihat langsung pada model fungsi permintaan Cobb-Douglas dengan data yang telah ditransformasi ke bentuk logaritma natural (LN) dengan melihat nilai koefisien dari masing-masing variabel bebasnya(Soekartawi, 2002). Koefisien elastisitas diperhitungkan hanya pada variabelvariabel bebas yang secara individual berpengaruh nyata terhadap variabel tak bebas. Variabel-variabel bebas yang dimaksud terdapat pada Tabel 4 berikut.

Tabel 4.

Elastisitas Permintaan Minyak Goreng Curah di Kota Denpasar

\begin{tabular}{llccl}
\hline \multirow{2}{*}{ Variabel } & \multicolumn{2}{c}{ Nilai Elastisitas } & \multirow{2}{*}{ Keterangan } \\
\cline { 2 - 3 } & Harga & Silang & Pendapatan & \\
\hline Harga minyak goreng curah $\left(\mathrm{X}_{1}\right)$ & $-2,18$ & & & $\begin{array}{l}\text { Permintaan elastis } \\
\text { Harga minyak goreng kemasan }\left(\mathrm{X}_{2}\right)\end{array}$ \\
Pendapatan rumah tangga $\left(\mathrm{X}_{5}\right)$ & & 3,59 & & $\begin{array}{l}\text { Substitusi } \\
\text { Barang inferior }\end{array}$ \\
\hline
\end{tabular}

Sumber : Data Primer (2018)

Kriteria elastisitas permintaan (Sudarman, 2000) meliputi:

1. Elastisitas harga atau $\mathrm{E}_{\mathrm{P}}$, dimana

a. $\quad E_{\mathrm{P}}>1$ artinya permintaan bersifat elastis

b. $\quad E_{\mathrm{P}}<1$ artinya permintaan bersifat inelastis

c. $E_{P}=1$ artinya permintaanbersifat unitary elastis

2. Elastisitas silang atau $\mathrm{E}_{\mathrm{C}}$, dimana

a. $\quad \mathrm{E}_{\mathrm{c}}$ bernilai positifberarti barang tersebut merupakan barang substitusi.

b. $\quad E_{c}$ bernilai negatif berarti barang tersebut merupakan barang komplemeter.

3. Elastisitas pendapatan atau $\mathrm{E}_{\mathrm{I}}$, dimana

a. $\mathrm{E}_{\mathrm{I}}$ bernilai positif berarti barang tersebut merupakan barang normal.

b. $\quad E_{I}$ bernilai negatif berarti barang tersebut merupakan barang inferior.

c. $\mathrm{E}_{\mathrm{I}}<1$ berarti barang tersebut merupakan barang kebutuhan pokok.

d. $\quad \mathrm{E}_{\mathrm{I}}>1$ berarti barang tersebut merupakan barang mewah.

Berdasarkan Tabel 4 diketahui bahwa koefisien elastisitas permintaan yang termasuk pada tabel telah dinyatakan signifikan berpengaruh terhadap permintaan minyak goreng curah. Hal ini dapat dijelaskan pada Tabel 3 mengenai pengaruh variabel bebas secara uji parsial (uji t). Tanda bilangan dan nilai koefisien elastisitas, bahwa nilai koefisien elastisitas variabel harga minyak goreng curah yang bertanda negatif artinya pengaruh berbanding terbalik dan koefisien lebih dari satu artinya elastisitas harga bersifatelastis. Elastisitas silang menunjukkan bahwa minyak goreng kemasan merupakan barang substitusidari minyak goreng curah karena koefisien 
bernilai positif. Elastisitas pendapatan menunjukkan bahwa minyak goreng curah merupakan barang inferior, dimana barang inferior merupakan barang yang berkualitas rendah meskipun terjadi peningkatan pendapatan justru mengurangi permintaan barang tersebut (Pracoyo, 2006).

\section{SimpulandanSaran}

\subsection{Simpulan}

Berdasarkan hasilpenelitian diketahui bahwa variabel bebas (harga minyak goreng curah, harga minyak goreng kemasan, harga daging ayam, jumlah anggota rumah tangga dan total pendapatan rumah tangga)secara simultan berpengaruhsignifikan terhadappermintaanminyak goreng curahdiKotaDenpasar.Namun, secara parsial variabel yang tidak berpengaruh signifikan terhadap permintaanminyak goreng curahhanyaharga daging ayam.Elastisitas harga menunjukkan bahwa permintaan minyak goreng curah bersifat elastis, elastisitas silang menunjukkan bahwa minyak goreng kemasan (merek apapun) merupakan barang substitusidari minyak goreng curah dan elastisitas pendapatan menunjukkan bahwa minyak goreng curah merupakan barang inferior.

\subsection{Saran}

Saran yang dapat penulis sampaikan adalah pada sisi stakeholders atau pihak bersangkutan baik pemerintah maupun para pemasok hendaknya memperhatikan ketersediaan minyak goreng curahsertamengatur regulasi mengenai kualitas minyak goreng curah agar mampu bersaing di pasaran kedepannya. Perludilakukan penelitian dalam areal lebih luas untuk mengetahui faktor lain yang belum dimasukkan dalam penelitian khususnya di Provinsi Bali.

\section{Ucapan Terimakasih}

Ucapan terimakasih penulis tujukan kepada para responden penelitian, dosen pembimbing dan dosen penguji, kerabat serta semua pihak yang telah membantu pelaksanaan penelitian hingga karya ilmiah ini dapat dipublikasikan secara e-jurnal.

\section{Daftar Pustaka}

Badan Pusat Statistik (BPS) Kota Denpasar. 2017. Kota Denpasar dalam Angka 2017. https://denpasarkota.bps.go.id/website/pdf_publikasi/Kota-Denpasar-DalamAngka-2017.pdf(diakses tanggal 25November 2017)

Berry, dkk. 2014. Faktor - faktor yang Mempengaruhi Permintaan dan Penawaran Minyak Goreng Curah di Kota Medan [Jurnal]. Program Studi Agribisnis Fakultas Pertanian Universitas Sumatera Utara, Medan.

Dinas Perindustrian dan Perdagangan Kota Denpasar. 2017. Pada lamanhttp://www.pasarlelangbali.com/harga-kebutuhan-pokok-hari-ini(diakses 20 September 2017)

Darnilawati, 1998. Analisis permintaan konsumen terhadap minyak makan di Kota Pekanbaru[Jurnal].Universitas Islam Negeri SUSKA Riau, Pekanbaru. 
Ketaren, S. 2008. Minyak dan Lemak Pangan. Cetakan Pertama. Jakarta Universitas Indonesia Press.

Nopirin. Ph.D, 2008, Pengantar Ilmu Ekonomi : Makro \& Mikro, Edisi ke-1, Cetakan Keduabelas, Yogyakarta, BPFE.

Pracoyo, A. 2006. Aspek Dasar Ekonomi Mikro. PT. Gramedia Widiasarana Indonesia. Jakarta.

Soekartawi. 2002. Analisis Usahatani. Jakarta: Universitas Indonesia

Sudarman, A. 2000. Teori Ekonomi Mikro: Buku 1. Edisi Ketiga. Yogyakarta. Badan Penerbit Fakultas Ekonomi (BPFE) Universitas Gadjah Mada.

Sukirno, S. 2013. Mikroekonomi Teori Pengantar. Jakarta:PT Raja Grafindo Persada.

Wijana, dkk. 2005. Teknopangan, Mengolah Minyak Goreng Bekas. Penerbit Trubus Agrisarana. Surabaya

Winarno F.G. 2004. Kimia Pangan dan Gizi. PT Gramedia Pustaka Utama. Jakarta 